\title{
Propuestas de realidad virtual y aumentada para el museo del s.XXI como laboratorio y espacio educativo
}

Virtual reality and augmented reality proposals for the museum of the 21 st Century as laboratory and educational space

\author{
Rubén Tortosa Cuesta ${ }^{a}$, Raquel Caerols Mateo $^{\mathrm{b}}$ Beatriz Escribano Belmar $^{\mathrm{c}}$ y Nuria \\ Rodríguez $^{\mathrm{d}}$ \\ ${ }^{a}$ Universitat Politècnica deValència , rtortosa@dib.upv.es; ${ }^{b}$ Universidad Complutense de Madrid, \\ rcaerols@ucm.es; ${ }^{\mathrm{c}}$ Universidad de Salamanca, Beatriz.escribano@usal.es; ${ }^{\mathrm{d}}$ Universitat Politècnica \\ deValència, nurodca@pin.upv.es
}

\begin{abstract}
Resumen
A finales del siglo $X X$, los medialab, como laboratorios de investigación $y$ producción transversal y participativos, comenzaron a ser fundamentales dentro del contexto histórico y cultural del momento, como un símbolo claro del paso del constructo de acción individual hacia la colectiva. Del mismo modo, los centros ciudadanos comenzaron a emerger en el siglo siguiente como paradigma del fenómeno cultural.
\end{abstract}

La génesis del concepto lab está en su diálogo directo con la sociedad, un laboratorio de medios, vinculado el contexto social en el que se imbrica. Colaboración y participación ciudadana, activismo social en un proceso de cocreación donde el propio ciudadano se empodera en la potestad de conformar el sentido que considera que deben tener las tecnologías de la comunicación. Él es protagonista de la conformación de la cultura digital, la cual le pertenece. ¿Y, no es esto en lo que se están convirtiendo o deberían convertirse los museos del siglo XXI y más, si desarrollan su actividad en el contexto digital?

Desde la concepción filosófica propuesta por Aby Warburg de las imágenes en un espacio visual dinámico, cambiante, mudable y abierto, en donde el tiempo toma un nuevo sentido, nos planteamos una nueva propuesta de la museografía virtual del siglo XXI. Así pues, para aproximarnos a la modelización de un museo virtual se hace necesario que identifiquemos la ruptura entre el museo como lugar solo para exposición y contemplación, de aquel en el cual se propone una nueva capa/espacio/temporal/virtual donde la interacción se convierte en elmotor y momento de la obra. Se pasa de una obra objeto a obra en proceso en el que lo colaborativo y educativo toman nuevos sentidos. Se trata de deconstruir el espacio de los museos y de las aulas para construir el espacio propio de lo digital, de sus narrativas. 
La multimodalidad marcará la línea metodológica central para el desarrollo de una narrativa interactiva, propiciando métodos y técnicas, en un espacio de museo virtual mediante experiencia inmersiva y seminmersiva, planteando propuestas en ambas plataformas. Desde estos objetivos, metodologías y propuestas tecnológicas como la realidad virtual y aumentada, obtendremos modelos metodológicos para desarrollar narrativas propias del espacio digital en un concepto de museo como laboratorio y espacio educativo.

Palabras clave: museografia virtual, laboratorio, educación, Realidad virtual, realidad aumentada.

\begin{abstract}
At the end of the XX Century, medialabs, working as crosssectional and participatory research and production laboratories, began to be elementary within the historical and cultural context of the moment. They represented a strong and clear symbol of the transition from the individual to the collective action construct. In a similar manner, the centers for the citizens emerged as a paradigm of the cultural phenomenon in the following century.
\end{abstract}

The genesis of the lab concept is in its forthright dialogue with society; a media laboratory linked to the social context where it is embedded. Collaboration and citizen participation, social activism in a co-creation process in which the citizen is empowered at the command of shaping the sense that the communication technologies should have. The citizen becomes the main character for the conformation of the digital culture, which belongs to him/her. And is not this prospective what 21st century museums should have, especially if they operate in the digital context?

From the philosophical conception suggested by Aby Warburg about the images in a dynamic, visual, changing, mutable and open space, where time takes a different meaning, an innovative proposition for the virtual museography of the 21 st century is suggested. Thus, in order to approach the pattern of a virtual museum, it is necessary to identify the breach between the museum understood as a place for exhibition and contemplation, and another one with a temporal/virtual/space new lawyer where interaction becomes the engine and instant moment of the artwork. It goes from an object to a work-in-process artwork in which the collaborative and educational concepts hold on new meanings. It is about deconstructing the space of museums and classrooms to build up the space of the digital and its narratives.

Multimodality is going to drive the main methodological line for the development of an interactive narrative, promoting different methods and techniques in a virtual museum space through immersive and semi-immersive experiences, offering proposals through both platforms. Taking these objectives, 
methodologies and technological proposals, such as virtual and augmented reality, methodological models will be obtained to develop original narratives in a unique museum concept as a laboratory and educational digital space.

Keywords: virtual museography, laboratory, education, narratives, Virtual Reality, Augmented Reality 


\section{Introducción}

La transformación de la concepción de museo como espacio para la conservación y restauración, a una ideación de museo con una clara mirada hacia lo social, al encuentro con el ciudadano, que se dio en torno a los años 80 , sumado a la irrupción de la tecnología digital en la vida cotidiana, han ido marcando el conjunto de variables que han conducido a los museos del siglo XXI a retos sin precedentes sobre su propia concepción, función y papel en la sociedad.

Las tecnologías creativas que fueron apareciendo desde finales del siglo pasado y principios del siglo XXI, aquellas con las que empezaron a dialogar de forma directa los artistas y sus procesos creativos, pueden considerarse como uno de los motivos impulsores de la creación de los medialab, pues podían dar respuesta a esa nuevo contexto por concebirse como espacios para la experimentación con las tecnologías y desarrollarse metodologías centradas en procesos que respondían a las narrativas de dichas tecnologías: participativas, colaborativas, co-creativas y procesuales. Sin embargo, siendo los museos espacios para la difusión y transmisión del Arte y que, por tanto, cabría suponer que las tecnologías creativas tendrían que jugar un papel relevante y enriquecedor en esa función de difusión y transmisión, se puede decir que, en realidad, ha sido de implantación muy paulatina y desigual. Es decir, con propuestas muy diferentes que muestran que aún hoy no se cuenta con estrategias claras, definidas y, por tanto, que las posibilidades narrativas de la tecnología digital, de las tecnologías creativas, no han sido asimiladas y entendidas plenamente aún.

Los medialab, situando como referente en este sentido a MediaLab Madrid, trataron de poner en práctica gran parte de esas tecnologías de forma pionera y experimental ya en los inicios del presente siglo. En el caso de MediaLab Madrid, jugó un papel precursor en la introducción del uso de Processing (2003) o Arduino (2005) en España, entre otras. El proyecto y convocatoria Interactivos? (2006) marcó el paradigma de todo lo descrito,

pero no solo desde las tecnologías implicadas sino $\mathrm{y}$, esencialmente, desde su propia concepción y experimentación, y que su impacto e incidencia han hecho que dicho proyecto siga vigente hasta hoy en Medialab-Prado ${ }^{1}$.

La pregunta ahora sería: ¿cómo se transformarían los museos y sus colecciones si una parte de su sede web, de su espacio virtual, se concibiera y diseñara desde estos planteamientos experimentales?

Por ello, se parte de la propuesta de que los medialab pueden ser un referente fundamental para arrojar mayor certidumbre y propuestas sólidas, para las necesidades y respuestas que reclaman los museos y centros de arte del siglo XXI. La siguiente cuestión o punto consistiría en identificar cuáles serían las narrativas y metodologías para su implementación y desarrollo.

\footnotetext{
${ }^{1}$ Más información en: https://www.medialab-prado.es/programas/interactivos
} 
Aby Warburg y su Atlas Mnemosyne (1924- incompleto tras la muerte del autor en 1929) representa para esta investigación, sin duda, una referencia fundamental, pues las narrativas de la visualidad que generó y aplicó en el citado Atlas, anclan sus raíces en el hipertexto, base conceptual de la narrativa digital y que multiplica sus posibilidades en un entorno que transforma el hipertexto en hipermedia y los diferentes canales de comunicación y plataformas en un contexto transmedia. Como el propio Warbug escribió en el reverso de su propio Atlas, creó un artefacto diseñado para hacer correspondencias, generando un juego de asociaciones significativas, traspasando el concepto del espíritu de su tiempo, esa no linealidad temporal que, así mismo, define la narrativa digital.

Pero no se puede citar a Warburg sin hacer alusión a la labor de André Malraux con su Musée imaginaire (publicado en el libro con el mismo título en 1947). Malraux defendía la idea de que el museo ya no tuviera que encerrar obras únicas, sino que gracias a la reproducción fotográfica, se liberase ese poder y se pudiera tener un museo personal a través de la reproducción de imágenes:

Malraux debatía las formas en que la reproducción mecánica, en particular, la fotografía, fue cambiando nuestra comprensión de las imágenes y la cultura visual en general (sin referencia al trabajo de 'La obra de arte en la época de la reproducción mecánica', 1936). Demostró cómo la disponibilidad sin precedentes de reproducciones estaba convirtiendo el pasado en y archivo, y desafió a los observadores a establecer conexiones entre las tradiciones visuales y motivos que hasta entonces se consideraban sin relación. (Huhtamo y Parikka, 2011, pág.7)²

En este sentido, Malraux se acerca al sentido que le proporcionó Aby Warburg al Atlas, ya que mediante la unión de diversas imágenes pretendía evocar analogías: en el caso de Warburg analogías para encontrar lo oculto en las imágenes, en el caso de Malraux analogías que acercasen al pasado.

La conjunción de la concepción del espacio medialab y las narrativas de las propuestas de Warburg (y aquellas cercanas a Malraux), marcarán la línea conceptual y propositiva de la presente investigación, como una vía de desarrollo para los museos en su ineludible diálogo y trabajo con las tecnologías creativas, y posibilitando así estrategias y metodologías de aprendizaje y comunicación como la multimodalidad.

\footnotetext{
2 Malraux discussed the ways in which mechanical reproduction, in particular photography, was changing our understanding of images and visual culture in general (without referring to Benjamin's 'Work of Art in the Age of Mechanical Reproduction', 1936). He demonstrated how the unprecedented availability of reproductions was turning the past into and archive, and he challenged observers to draw connections between visual traditions and motifs that had until then been considered unrelated" (Traducción de los autores).
} 


\section{Objetivos}

El objetivo general que se marca en la presente investigación es conformar un marco de referencia sobre el que sustentar la propuesta de lo que entendemos que son y deberían ser los retos del museo del siglo XXI.

A partir de ahí, los objetivos específicos serían:

- Analizar aquellas propuestas y ejemplos que han marcado una innovación en las líneas de trabajo que se plantean en la presente investigación.

- Examinar la consideración de un espacio de aprendizaje en el museo del siglo XXI.

- Describir aquellos resultados concretos desarrollados por alguno de los investigadores implicados.

- Mostrar que exista la posibilidad de una realidad tangible de lo que desde esta investigación se entiende por el museo del siglo XXI, como espacio de aprendizaje, colaborativo y educativo.

\section{Desarrollo de la investigación}

\subsection{Los medialab como espacios referentes para museos más sociales, participativos y co- creativos.}

Como se señaló con anterioridad, los medilab empiezan a tener una presencia significativa en las sociedades contemporáneas a finales del pasado siglo como respuesta a la inclusión de las tecnologías digitales y creativas en las sociedades contemporáneas y, además, y en estrecha relación a esa circunstancia, del paso de la acción individual a la colectiva. Esa transformación en los procesos creativos desde una concepción de dinámicas colaborativas y participativas no son sino una renovación proveniente de las Vanguardias Históricas, hecho que se percibió de manera mucho más nítida desde finales de los años 60 , exponencialmente con la conjunción arte-vida del movimiento Fluxus o el empeño de los artistas por humanizar y democratizar el acceso a las tecnologías y la producción de conocimiento.

Las reflexiones de las investigadoras Ortega y Villar en el artículo "El modelo Media Lab: contexto, conceptos y clasificación. Posibilidades de una didáctica artística en el entorno revisado del laboratorio de medios" (2014) refuerzan y evidencian el sentido de los presentes planteamientos y la génesis que subyace en el concepto de medialab y que describe una línea directa con el camino iniciado por los artistas de finales del siglo XIX y los artistas de las Vanguardias Históricas: "El concepto de colaboración (Laddaga, 2011; Rodrigo, 2011; Kester, 2010; Ardenne, 2006), tal cual lo entendemos en nuestra investigación, está caracterizado por traspasar las estructuras de producción y distribución destinadas a las élites y abrirse al ámbito público.” (Ortega y Villar, 2014, pág.151).

De este modo, se propició la transformación desde un centro expositivo tradicional, donde se priorizaba el objeto artístico sobre la experiencia del visitante, al paso de algunos intentos de museos del s.XXI donde la experiencia del visitante comenzó a ser la prioridad en un espacio 
dinámico y educativo, al paso hacia medialab como un lugar abierto de diálogo, colaboración y producción artística con un carácter constructivista. Surge así un ecosistema creativo, simultáneamente dedicado a la reflexión y el debate; a la investigación y la producción, a la formación y la socialización, la exposición y la difusión, transformando la concepción y experiencia convencional y compartimentada de la relación entre autor, obra y público en un entorno permeable y compartido (Caerols y Escribano, 2019). La muestra más directa de ello es el citado Interactivos?, que se propuso convertir el espacio expositivo en un lugar donde compartir experiencias, adquirir conocimientos y debatir ideas, en un híbrido entre taller seminario - exposición.

En este nuevo contexto también se vieron modificadas las clásicas jerarquías de producción entre autores, proyectos, procesos, mediadores y público, convirtiéndolas en una relación rizomática, horizontal, no lineal y abierta de creación colectiva y participativa, generadora de comunidades temporales con intereses compartidos, cercanas a lo que sería el funcionamiento taller donde poder aprender de los otros.

Todo ello no deja de ser hipertexto, hipermedia en la dirección de las narrativas warburianas, abriendo paso al contexto y posibilidades de las narrativas transmedia en un contexto multiplataforma y propiciando un espacio educativo que posibilita y potencia el aprendizaje multimodal, constructivista e, incluso, crítico.

\subsection{La interactividad y la interacción como herramientas y narrativas para la co- creación: hacia un modelo de museo virtual como espacio colaborativo y de aprendizaje.}

En las dos últimas décadas, la sociedad ha experimentado toda una serie de revoluciones tecnológicas crecientemente significativas -como se ha señalado en la introducción- cuya capacidad para desarrollar y crear nuevos escenarios virtuales en el mundo real van a ser determinantes. En el entorno actual, la comunicación, la multiplicidad, la heterogeneidad, la velocidad y la pluralidad van a ser fundamentales y, tanto las prácticas artísticas que emplean los medios digitales y de telecomunicación, como los diversos medios de difusión: museos, galerías, fundaciones, redes sociales, etc.; van a tener que adaptarse a los nuevos cambios estéticos y a los nuevos lenguajes que representan nuevos imaginarios a través de la combinación de datos interactivos. La información y los datos hay que convertirlos en un nuevo conocimiento dentro de un mundo donde la realidad es fluida y cambiante. Quizás haya que, primero, desaprender y entender cómo viaja la imagen a través de canales virtuales para materializarse en la pantalla o a pocos centímetros, casi dentro de la retina.

Por todo ello, la práctica artística demanda una nueva reconsideración de la función del artista y fundamentalmente de los canales de exposición, visualización, espacio y comercialización, ya que también y no menos importante, va a ser el papel del observador/usuario: "El consumo de este tipo de prácticas se articula en torno a la comunicación y la producción de significados a través de estructuras de interacción mediática entre los observadores/usuarios -comunidad de productores de sentido- que transforman el objeto del arte en un sistema en constante proceso" (Berenguer, 2004, pág.12). Los usuarios ya no se detienen delante de una obra de manera estática y contemplativa heredada de la tradición. Van a tener un papel primordial como parte 
de los que van a producir, en tiempo real, dichas obras, en tanto que como apunta Berenguer, habilitan un territorio de comunicación sobre la base de una sistematización empírica de datos interactivos. El usuario va a situarse en una frontera entre lo real y lo virtual, cruzando constantemente un estrecho, casi ínfimo paso que los separa. Ello va a generar una revolución en los espacios tradicionales que hasta ahora se han validado como lugares de exposición de las obras de arte.

Los espacios van a ser determinantes y los actores, estos son: artistas, público/usuarios, comisarios, galeristas, directores de museos, etc., van a establecer nuevos roles en esos espacios que van a dejar de ser exclusivamente físicos, y se van a convertir en lugares híbridos y virtuales, con estructuras inestables e indeterminadas como auténticos espacios de uso e intercambio, como puedan ser los laboratorios.

Si como se viene estableciendo, el artista y el usuario van a formar parte de la propia producción de la obra de arte, ya que su naturaleza es la interactividad, el usuario va a provocar la interacción, estableciendo una relación de comunicación a partir de las interfaces. Esto lleva a una hibridación de redes y procesos, ya que la interacción es el eslabón que los une. El propio sistema establece que el dispositivo sumado a la red genera el proceso, produciéndose la creación y desarrollo de la obra, siendo una conducta inédita de los participantes que son también receptores. De esta manera y en términos conceptuales, asistimos a un entorno líquido resultante de la interacción, que:

No sólo sugiere un entorno que tiene la característica de circular de un lado a otro sin detenerse, sino también, y esto es significativo, la de definir un entorno que puede adquirir la forma del recipiente que lo contiene que, en nuestro caso, correspondería a la capacidad de interacción que los propios dispositivos de los sistemas de interfaz desarrollan al articularse entre sí. (Berenguer, 2004, pág. 58)

Esta idea por su parte Derrick De Kerckhove ya se refirió al "Ma" en la cultura japonesa, como un fluido continuo, conductor de todo tipo de energías, aludiendo a la estructura de relaciones entre las personas y los objetos (De Kerckhove, 1999).

Si el espacio físico deja paso al virtual, la pregunta es ¿cuál va a ser el papel de los espacios tradicionales como lugares de exposición y contemplación de las obras de arte?. Pensamos que son espacios/lugares que tienen que ver más con la idea de laboratorios participativos en el que los procesos son ya parte de la obra, en donde artistas y usuarios se retroalimentan de ellos y su interactividad.

Lo señalado evidencia que la base conceptual sobre la que se crearon los medialab y las metodologías que se desarrollaron, podría ser una respuesta a las necesidades de transformación de las instituciones museísticas, generando espacios nuevos hibridados y, sin ninguna duda y, especialmente, a la virtualización de colecciones, archivos, según las narrativas propias del espacio digital. Y se establece aquí virtualización porque se debe superar la mera digitalización 
de las colecciones y archivos, para transformarlas en experiencias, aquellas inherentes y que definen el espacio virtualizado.

Todo ello define y asienta los pilares de lo que sería un espacio colaborativo y participativo, que en el propio hacer y recorrido, la propia colección entraría en la narrativa de ir redefiniéndose y co-creándose en el propio proceso participativo y colaborativo de la acción del visitante en sí con la colección, conllevando a un proceso de aprendizaje, de educación constructivista, y con ello, alcanzando uno de los principales objetivos de la institución museística, conformar el museo en un verdadero espacio educativo.

Pero ¿qué metodologías y narrativas serían las propias a aplicar? Sin duda, las posibilidades de narrativas participativas, colaborativas y co-creativas solo tienen su porqué, su posibilidad y su desarrollo en el hipertexto, en el entorno hipermedia que posibilita el contexto digital mediante la maquinaria asociativa warburiana sumado a lo transmedia y definiendo así una entorno de aprendizaje que posibilita la multimodalidad.

En este espacio y características, y teniendo en cuenta aquellas tendencias de educación en museos, la relación de enseñanza-aprendizaje se movería sobre aquella educación constructivista donde se explora la relación entre el trabajo del artista, el contexto e intereses de los participantes y los contenidos que se desean que sean aprendidos. Aquí es importante el aprendizaje cooperativo e interacción personal, para que el usuario aprenda también de otros visitantes, basándose en la teoría educativa del constructivismo (Hein, 1998). También se movería teniendo en cuenta la tendencia de educación crítica, aquella que ofrece generar nuevos planteamientos o ideas a partir de los temas o problemas base que establece la institución (física o virtualmente), y a partir de los que se realizan todo tipo de actividades. En ella, la voz del usuario-visitante en la interpretación de las obras es fundamental, dejando que cada persona pueda crear y construir su relato particular. La educación es vista como un proyecto activista, lejos de la versión legítima y unidireccional tradicional de los museos, teniendo ahora en cuenta que puede ser una forma de producir y distribuir cultura para transformar la sociedad (López, 2017).

Todo lo dicho, sentaría las bases de lo que, desde el presente estudio, definiría el museo del siglo XXI, tanto en lo referente al espacio físico como, y especialmente, al espacio virtual en relación a sus propias narrativas.

\section{Desarrollo de la innovación: hacia los museos de la experiencia}

La didáctica en su concepción actual tiene presencia en los museos desde la segunda mitad del s.XX, poniendo el foco en la transmisión de los contenidos a partir de estrategias pedagógicas basadas en el estudio del espectador y su capacidad de asimilación cuando interactúa con los contenidos de una muestra expositiva.

Sin embargo, la didáctica en los lugares museísticos tiene su origen en la Ilustración y empezó a tener especial relevancia a partir de la Revolución Francesa, cuando se difundió la idea del 
museo como espacio para aprender y culturizarse. Desde el siglo XVIII, los museos fueron concebidos como espacios arquitectónicos que favorecieron el acercamiento del espectador hacia las obras de arte, produciéndose una forma de comunicación unidireccional desde el museo hacia un público homogéneo, cuya acción esperada era la visualización de las colecciones. En la búsqueda de nuevas audiencias, se desarrolló dentro de las mismas instituciones, otra tipología de espacio para albergar las exposiciones temporales que, de alguna manera, dialoga no sólo con las obras de las colecciones permanentes, sino que proporcionaba nuevas vías de investigación en la presentación expositiva y una aproximación hacia el concepto de laboratorio como espacio propicio para la experimentación y la reflexión (Ibáñez, 2010).

La especificidad creciente de las instituciones museísticas y la inauguración de museos de ciencia y tecnología como el Palais de la Découverte de París (Francia) en 1937 y el Exploratorium de San Francisco (EE. UU.) en 1969, marcaron un cambio en la manera de concebir la museología, ya que, en lugar de poner el foco en los objetos y su conservación, lo pusieron en las ideas que presentan y la posibilidad del visitante para interactuar con los diversos módulos (Bengtsson, 2020). Este modelo propuesto por John Dewey ponía el foco en el aprendizaje adquirido a través de una actitud activa, porque según Dewey, se aprende "haciendo", su teoría del conocimiento se basa en la interacción básica que se produce entre el individuo y el mundo, uniendo información, educación y diversión a través de una metodología de proyecto.

Un ejemplo emblemático ha sido el museo interactivo de ciencia Exploratorium que el profesor de física Frank Oppenheimer fundó en 1969 en San Francisco y responde a la nueva tipología de museos mencionada. Por otro lado, se puede considerar que fue pionero en implementar la filosofía del museo de la experiencia. La idea de Oppenheimer se basa en democratizar la enseñanza científica a través de un museo focalizado en la experiencia, sin colección, donde los visitantes pueden interactuar con dispositivos construidos para tal fin y descubrir así todo tipo de fenómenos naturales: electromagnéticos, ópticos, físicos o atmosféricos. Con el denominador de "museo de arte, ciencia y percepción", proponía la exhibición de los conocimientos y los hitos científicos más emblemáticos de nuestra historia. Actualmente, el Exploratorium está considerado como un modelo que replanteó la educación científica y un referente crucial para la creación de los posteriores espacios expositivos, replanteando la relación entre exhibición, pedagogía e interacción. La financiación de este centro, que contó con el apoyo de la administración pública, también marcó un referente en el que las instituciones daban respaldo a este tipo de museos como complemento a la enseñanza pública. El Exploratorium anticipó la tendencia de permitir que los visitantes aprendieran a través de la exploración con todos sus sentidos y la realización de actividades. El ejemplo de este tipo de museo se popularizó rápidamente, generando una corriente museística que centra el interés en el "hacer" frente a la experiencia contemplativa tradicional (Sanchis, 2017).

Paulatinamente, los elementos tecnológicos comenzaron a formar parte de los recursos necesarios para introducir narrativas más experimentales en los recorridos propuestos por comisarios y especialistas. Wolf Vostel, entre otros artistas que trabajaron en esa dirección, 
comenzó a disponer módulos de televisores como artefactos artísticos, lo que dio pie a un uso más funcional, introduciendo el lenguaje audiovisual con todos sus recursos como un elemento tecnológico que superponía una capa de contenido informativo y en movimiento distinto al otorgado por la mera disposición de las piezas por el espacio.

En la actualidad, la tecnología digital ha calado en la sociedad. Su uso se ha extendido exponencialmente y no se limita solo al ámbito cultural o al entretenimiento, sino que es un sello identitario de la sociedad contemporánea. Museos como el Exploratorium propusieron un modelo museográfico donde se realizaron grandes esfuerzos por unir información, educación y diversión, pero estas variables en sí mismas parecen agotadas ya que la cultura digital y sus avances tecnológicos ofrecen una renovación constante en los modos de interacción y todos los recursos que las tecnologías digitales nómadas ofrecen ante el cambio de paradigma en la cultura digital.

Llegados a este punto, cabe realizarse las siguientes preguntas: ¿Realmente la interactividad a través de la realidad aumentada o la realidad virtual provoca un cambio en los modos de interacción con las colecciones o las muestras expositivas? ¿Podrían llegar a asumir un papel protagonista en la comunicación multimodal? ¿Los museos o centros de arte aprovechan el potencial expresivo que ofrecen estos recursos digitales?

Para formular algunas respuestas, se describirán a continuación algunos casos de éxito que fueron pioneros en el ámbito museográfico y en el territorio nacional cuando es posible configurar narrativas transmedia como un recurso conceptual que legitima el uso de lo tecnológico en los montajes contemporáneos.

Un ejemplo de ello fue el rediseño de la identidad visual del Museo del Prado realizada por Fernando Gutiérrez y Mikel Garay, tratando de mejorar las estrategias de comunicación que proyectaba la institución hacia el exterior o la pluralidad de las actividades programadas de la muestra expositiva "Piedad y terror en Picasso" organizada por el Museo Nacional Centro de Arte Reina Sofía para conmemorar el $80^{\circ}$ aniversario de la pintura Guernica de Pablo Picasso. Sin embargo, será la muestra "La ilusión del Lejano Oeste" (2015), comisariada por Miguel Ángel Blanco con el apoyo del departamento de didáctica del Museo Thyssen-Bornemisza, la que evidenciará con mayor solvencia, las posibilidades de difusión que se alcanza en un proyecto museográfico, cuando se combinan distintos medios de comunicación dentro de un mismo proyecto expositivo, otorgándole una nueva categoría que denominaremos: muestra transmedia y que analizaremos posteriormente. Esta exposición reunió una extensa colección de obras emblemáticas de la pintura norteamericana del siglo XIX que fagocitaron la imagen que tenemos del Far west pero lo relevante, desde nuestro punto de vista, fue el esfuerzo que realizaron los diferentes agentes implicados en la construcción de un relato, proponiendo una narrativa atractiva que fuera capaz de aglutinar la extensa red de actividades alrededor de este foco central: los pasos de aquellos artistas americanos que mostraron el Oeste americano y ayudaron a crear el mito del Far West en nuestra cultura. Por ello, organizaron talleres para adultos donde se les mostraba técnicas de ilustración para poder realizar un cuaderno de campo, diseñaron aplicaciones gratuitas para conocer a los grandes pintores norteamericanos, 
publicaron un $\mathrm{CD}$ recopilatorio de música y buscaron distintas audiencias a través de programas de radio, entre otras acciones. ¿No es esto lo más cercano al citado proyecto de Interactivos?

Otro ejemplo reciente fue la muestra "Lecciones de arte" generada por la misma institución y concebida como un espacio que albergaba la propuesta artística de creadores contemporáneos como Antoni Muntadas, Cinthia Marcelle, Dennis Adams, Eva Kot átková, Dora Garcia, Pavel Kogan, Erwin Wurm o Rineke Djikstra, en las que se cuestionaba cómo se produce y reside el conocimiento. Esta muestra plantea abiertamente el papel de la institución como un lugar para reflexionar sobre la experiencia personal y permitía al público convertirse en agente activos de los cambios formales que se produjeron en las distintas salas que alberga la muestra y que formarán parte del proceso de experimentación e investigación que de nuevo el equipo de didáctica llevó a cabo en el diseño de la muestra.

El significado del término transmedia está indiscutiblemente asociado a la elaboración de un itinerario narrativo y hace referencia al tipo de relato que se construye y adapta a las diferentes posibilidades comunicativas que ofrecen cada uno de los formatos y canales de comunicación. El relato parte de un mismo origen, pero se disfraza y adapta a las especificidades de cada medio, aprovechando las ventajas de cada uno. Resulta un excelente ejemplo de este nuevo paradigma, la muestra "El Bosco. La exposición del V centenario" organizada por el Museo del Prado en 2016. Tal y como analizan Mateus y Grifeu en su artículo: "Transmedia Storytelling and Its Natural Application in Museums. The Case of the Bosch Project at the Museo Nacional del Prado", esta exposición ramificaba sus contenidos a través de distintos medios que aportan aspectos relevantes al conjunto de la propuesta (Rodríguez et al, 2019). ¿No es esto el hipertexto, no es esto el hipermedia? ¿No supone esta propuesta un potente artefacto para hacer saltar correspondencias? en relación con nuestras referencias a Warburg.

\section{Resultados}

Desde la Facultad de Bellas Artes de Valencia se han abordado estas cuestiones en dos proyectos interactivos que han servido para experimentar y acometer algunas de las cuestiones que se han planteado a lo largo de esta propuesta: investigar sobre las posibilidades que la capa tecnológica puede incorporar en una muestra expositiva a través de los dispositivos móviles y en concreto, gracias a la realidad aumentada y virtual.

El proyecto expositivo "Pensar con las manos. Isidro Ferrer \& Pep Carrió" presentado en la sala Josep Renau (junio 2013) y que luego pudo itinerar a diferentes ciudades como Madrid, Miami, Chicago y Washington entre 2014 y 2015, fue la investigación pionera que se llevó a cabo desde Unit Experimental en esos años ${ }^{3}$. Este proyecto permitió experimentar y comprobar lo que denominamos como "nuevos modos de mirar", aprovechando las ventajas lúdicas e

\footnotetext{
${ }^{3}$ Unit experimental es un equipo transdisciplinar de investigación de la Universitat Politècnica de Valencia que se crea en 2012 y está formado por investigadores de la Facultat de Belles Arts de València y la Escola Tècnica Superior d'Enginyeria informàtica. https://unit.webs.upv.es/
} 
informativas que ofrecen los medios digitales sobre los cuadernos y las obras físicas de los diseñadores e ilustradores Isidro Ferrer y Pep Carrió. Durante el año que dedicamos a desarrollar el proyecto surgieron, además, otras ideas para amplificar la experiencia de la visita y el modo de acercarnos a las obras. Así, los personajes representados en los cuadernos cobraban vida estableciendo distintos lenguajes gráficos resultantes del intenso proceso de investigación en torno a las posibilidades de esta tecnología. En unos casos, mediante animaciones en dos dimensiones pudimos dar movimiento a aquellas imágenes que así lo sugerían en el boceto del autor. En otros, en cambio, el boceto adquiría apariencia de obra finalizada y movimiento mediante la representación tridimensional, llegando a desarrollar cierta interacción con los elementos representados.

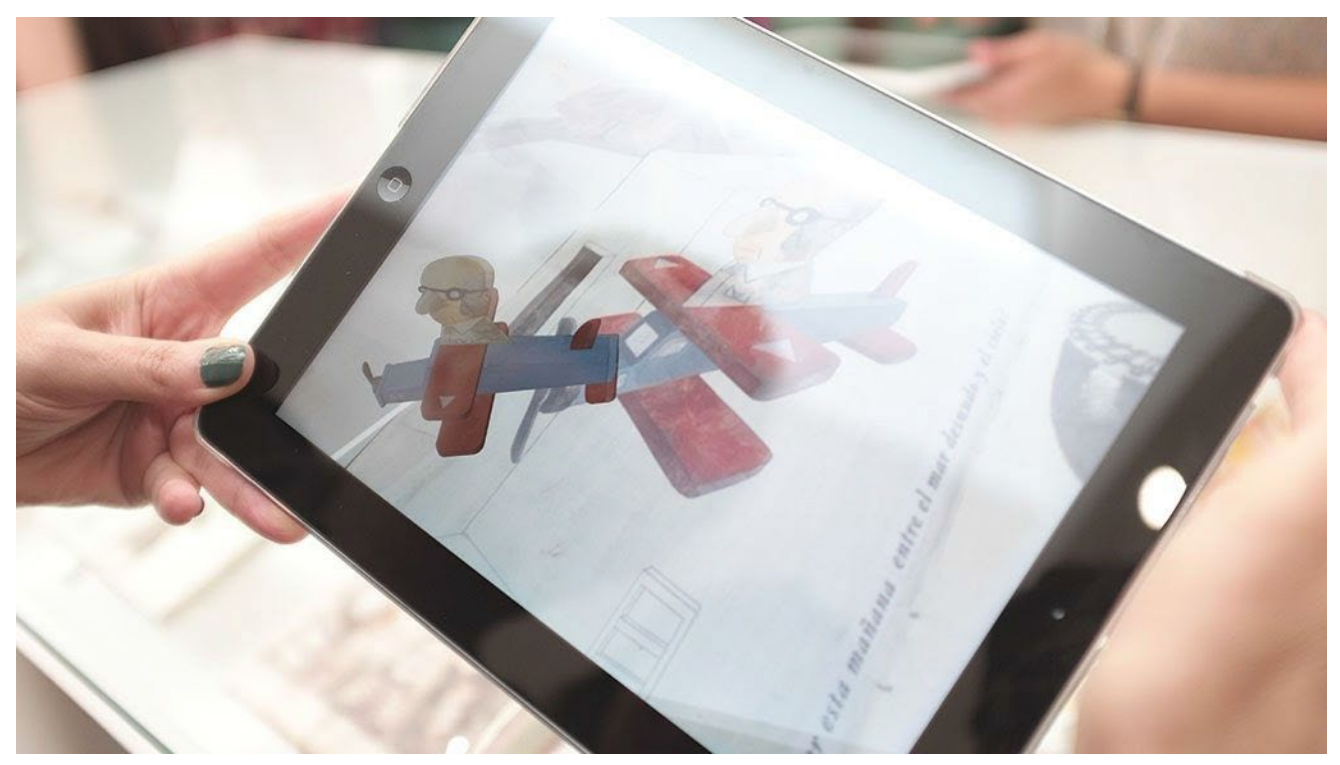

Fig. 1 Realidad aumentada en la exposición Pensar con las manos. Isidro Ferrer y Pep Carrió. Sala Josep Renau (Facultad de Bellas Artes, Valencia 31/05 a 26/07/2013). 


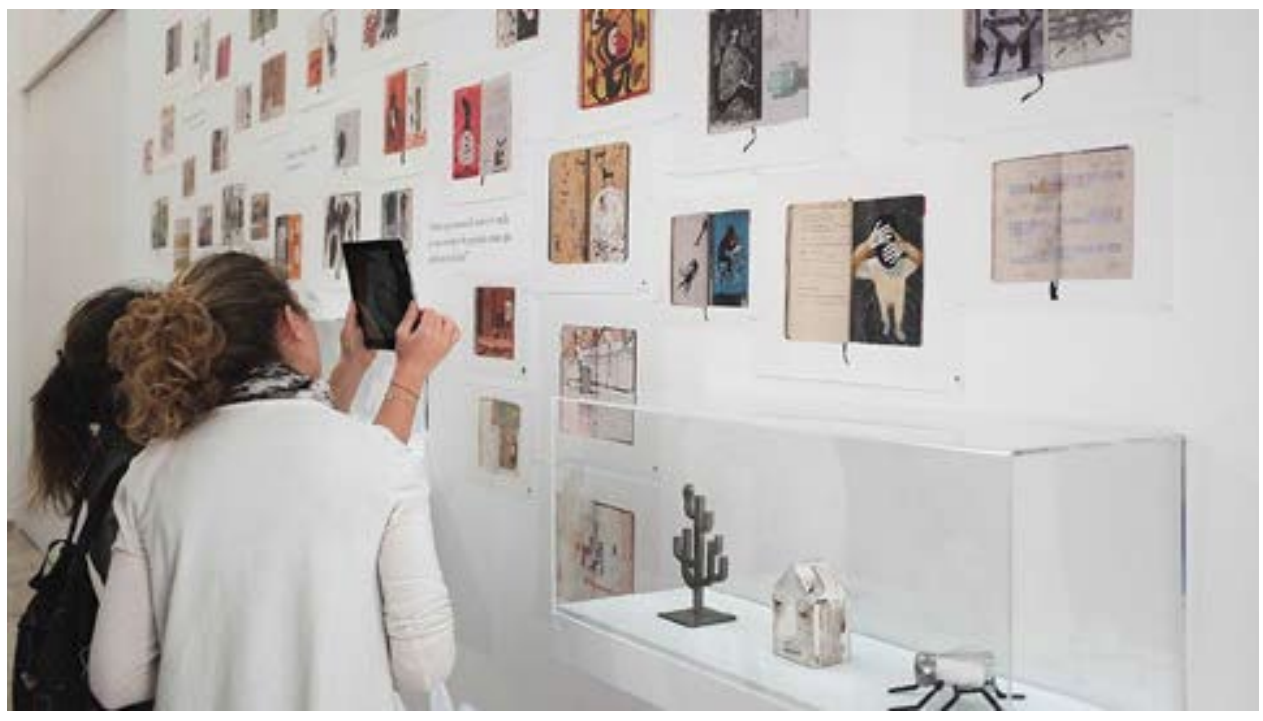

Fig. 2 Este proyecto realizó una itinerancia internacional a CCEMiami y Galería Artisphere, Washington en 2014 y al Instituto Cervantes de Chicago en 2015.

Finalmente se realizaron 6 tipologías distintas de interacción y se desarrolló una aplicación interactiva titulada "Los Cuadernos" para hacer alusión al nexo creativo entre los dos autores que, una vez descargada en los dispositivos móviles de los visitantes, les permitía descubrir el contenido digital: unas sesenta interacciones repartidas por el recorrido de la sala como animaciones $3 \mathrm{D}$ y $2 \mathrm{D}$, vídeos documentales o cuadernos interactivos, entre otras.

Tras esta propuesta inicial, se realizó otro proyecto experimental: Ana Juan, dibujando al otro lado, gracias a la financiación del Ministerio de Industria y Competitividad para desarrollar una nueva propuesta de uso de la tecnología en muestras expositivas. En esta ocasión, Unit Experimental trabajó a partir de la obra de la ilustradora Ana Juan para introducir la narratividad como eje vertebrador del proyecto. Para ello, se ideó una aventura interactiva en 3D y construyeron en realidad aumentada y a tamaño real, algunos de los personajes principales de su álbum ilustrado Snowhite.

Los visitantes podían encontrarse con la taberna y los siete enanitos disfrutando de sus bebidas o del paseo de Snowhite por la sala, así como ver a la coqueta madrastra que, tumbada en su diván, cepillaba su cabello mientras su mascota daba saltos. A simple vista, nada de todo esto estaba sucediendo y solo era posible visualizarlo a través de la cámara de los dispositivos móviles. En esta ocasión, se concibió toda la sala de exposiciones como un tablero de juego donde los visitantes podían interactuar con los personajes de realidad aumentada y resolver los retos lúdicos propios de un video juego que titulamos Erthaland, Snowhite's Mystery Tale. La exposición se presentó en el Museo ABC (Madrid) y se planteó como una experiencia transmedia, donde los formatos expositivos y las actividades se complementaban para ofrecer 
una experiencia estética que combinaba aspectos lúdicos, narrativos y emocionales con el objetivo de ofrecer un recorrido significante. Según los datos aportados por la institución, gracias a esta tipología expositiva, la afluencia de visitantes durante los cinco meses de la muestra aumentó hasta en un $87 \%$ según su registro diario, convirtiéndose en un nuevo hito de público para el museo.

Tras la experiencia de Unit Experimental en las iniciativas expuestas, se considera que el uso de la tecnología en una muestra expositiva o como parte de ella, debe estar justificado tras un estudio minucioso y pormenorizado para argumentar de manera coherente, la estrategia multimodal más adecuada, aprovechando la investigación previa para evidenciar qué contenidos digitales deben ramificarse y de qué modo, tratando de acreditar qué vías de comunicación serían las más adecuadas para afianzar la narrativa global de la muestra.

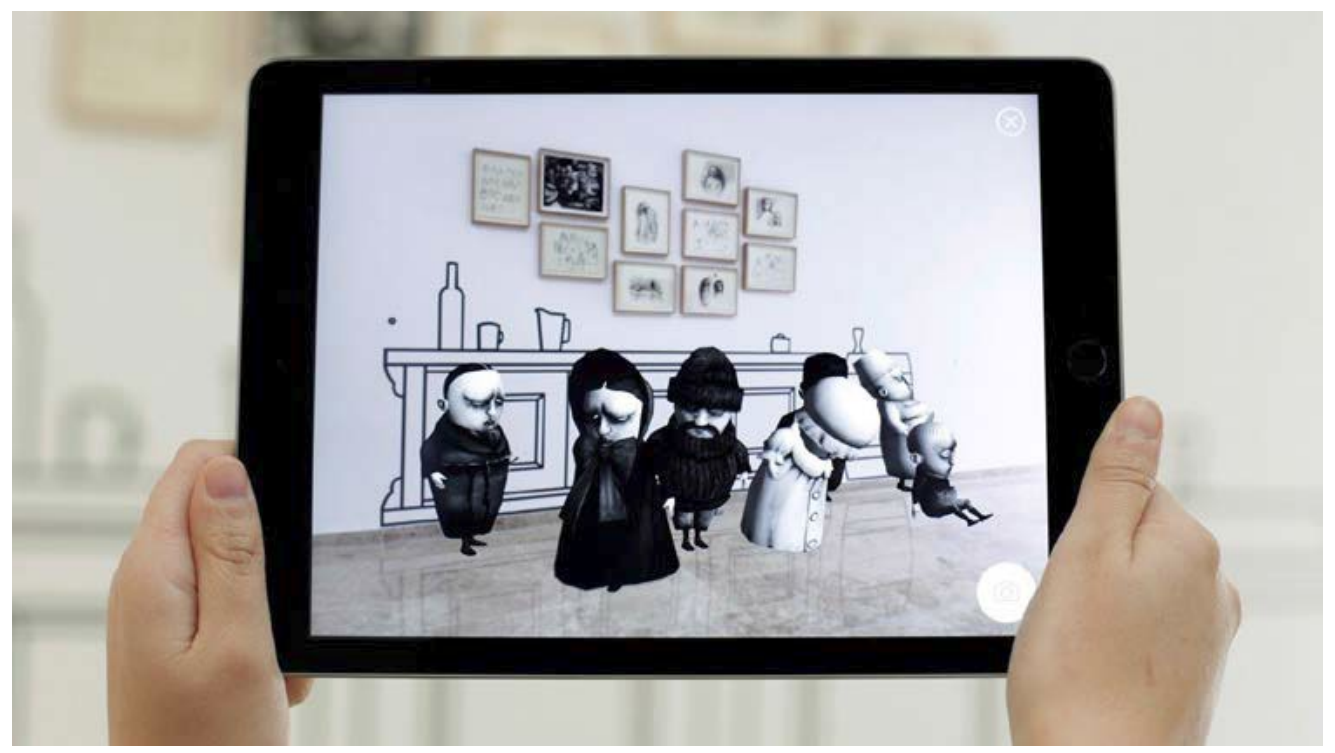

Fig. 3 Realidad aumentada para la aplicación Ana Juan, dibujando al otro lado presentada en elMuseo ABC, Madrid en 2017.

\section{Conclusiones}

El presente estudio trata de dibujar un marco teórico-práctico de referencia que se ha ido construyendo a partir de los proyectos de investigación que han precedido a los investigadores implicados en dicha investigación.

Los medialab, como se ha podido observar a lo largo de este estudio, surgieron en la necesidad misma de dar respuesta a los retos de la tecnología digital en la sociedades contemporáneas. En esa frontera de creación, experimentación, producción y muestra de dicha producción, que no 
era museo pero que, precisamente, nació para dar respuesta a esas necesidades sociales frente a la experimentación y creación con las nuevas tecnologías y a lo que no daban respuesta los museos, produciéndose, a la par, una transformación de éstos en espacios más sociales, al encuentro del ciudadano, concebidos también como espacios de aprendizaje que, de algún modo y, en ese sentido, se acercaban a los medialab. Es decir, el surgimiento de éstos y la transformación de aquellos, fueron consecuencia de un nuevo contexto en cuanto al concepto de las artes, de la creación artística y sus procesos, del patrimonio cultural, a lo que se sumaba, la llegada de las nuevas tecnologías.

Por ello, todo lo estudiado y expuesto en la presente investigación, configura para nuestros intereses presentes y futuros, un marco de referencia sólido con el que intentar dar respuesta a una nueva realidad en la difusión y transmisión del patrimonio en su intersección de las nuevas tecnologías y los nuevos públicos y audiencias.

Por ello, además de la primera referencia a los medialab como espacios que aportaron nuevas metodologías en el contexto de las tecnologías creativas, se ha hecho un pequeño apunte de los conceptos clave, como la interacción, la interactividad, sus tecnologías asociadas, como la realidad virtual y aumentada, los entornos colaborativos y de aprendizaje que ellas posibilitan, y sus nuevas narrativas y metodologías de aprendizaje, teniendo también como referencia las nuevas teorías desarrolladas en el contexto de la educación.

Finalmente, se ha materializado en experiencias desarrolladas por instituciones de referencia así como por las realizadas por los propios investigadores implicados en el presente estudio a través de Unit Experimental, marcando una línea de trabajo concreta, que evidencia que las experiencias en el entorno virtual deben ser propias de las narrativas y experiencias que proporciona el propio espacio virtual. No es pues, una sustitución de la experiencia presencial, sino otra muy distinta a la presencial, o dicho de otro modo, otra que no puede proporcionar la presencial, así como la presencial tampoco puede ofrecer los relatos, narrativas y experiencias que la virtual, pudiéndose ésta, a la par, enriquecerse con las tecnologías.

Se concluye pues, que son dos realidades diferentes con experiencias diferentes, que se pueden enriquecer en su retroalimentación. Por tanto, se puede enriquecer la experiencia presencial con las posibilidades tecnológicas y se deben generar narrativas y metodologías propias del espacio virtual, que no sean una analogía de la experiencia física con pequeñas simulaciones, sino propia del lenguaje y funcionamiento virtual, del espacio virtual. 


\section{Referencias}

ALCALÁ Mellado, J. R., et al. (2009). ¿Cómo se cuelga un cuadro virtual? Las exposiciones en la era digital. Gijón: Trea.

BENGTSSON, A. (2020). Multimodalidad e interactividad en algunas formas de contar la ciencia.

Cuadernos del Centro de Estudios en Diseño y Comunicación, nº9: 69-91.

BERENGUER, F. (2004). La interfaz electrónica. Sobre las prácticas artísticas en torno a los flujos interactivos. Valencia: Universitat Politècnica de València.

CAEROLS, R. y ESCRIBANO, B. (2019). Medialab Madrid 2002-2006. Cultura participativa y activismo social en Madrid. Artnodes. n. ${ }^{\circ}$ 24: 111-120. UOC. http://dx.doi.org/10.7238/a.v0i24.3273

KERCKHOVE, D. (1999). La piel de la cultura. Investigando la nueva realidad electrónica. Barcelona: Gedisa

HEIN, G. (1998). Learning in the Museum. Londres: Routledge.

HUHTAMO, E. y PARIKKA, J. (eds.) (2011). Media Archaeology. Approaches, Applications and Implications. Berkeley / Londres: University of California Press.

IBÁÑEZ, M. (2010). IVAM-Centre del Carmen (1989-2002): la exposición como obra de arte. Valencia: Institució Alfons elMagnànim.

HERNÁNDEZ, F., MARTÍNEZ, T., y ROJO, M. (2010). Los límites de la interactividad. En J. Santacana, y C.Martín,Manual de museografía interactiva. Gijón: Ediciones Trea.

LÓPEZ, E. (2017). "La educación artística y estética en museos, centros de arte contemporáneo y lugares de patrimonio" en Caeiro, M. et al. Aprender, crear, enseñar. Didáctica de las artes plásticas y visuales en educación primaria. La Rioja: UNIR Editorial.

MATEOS-RUSILLO, S.M. y GIFREU-CASTELLS, A. (2018). Transmedia Storytelling and Its Natural Application in Museums. The Case of the Bosch Project at the Museo Nacional del Prado. Curator. The Museum Journal 61, n. 2. 301-313.

MUSEO NACIONAL DEL PRADO. "10 claves. Proyecto de identidad visual para el Museo del Prado". Consultado el 17 de agosto de 2019, https:/www.museodelprado.es/actualidad/multimedia/10claves-proyecto-de-identidad-visual-para-el/02c649da-965f-a307-3cd3-8e9d6759c5ca

ORTEGA, I. y VILLAR, R (2014). El modeloMedialab: conceptos, contextos y clasificación. Posibilidades

RODRÍGUEZ, N. et al. (2019). "Diseño digital transmedia para espacios expositivos” en Museo. Imagen. Sentidos, editado por Ángel Pazos-López y Alejandra Alonso Tak. Monográfico temático, Eikón Imago 14: 393-412.

SALMÓN, C. (2008). Storytelling. La máquina de fabricar historias y formatear mentes. Barcelona: Península.

SANCHIS, Á. (2017). Diseño de experiencia de usuario en la museografía interactiva. Metodología proyectual para aplicaciones móviles de museos y espacios expositivos [Tesis doctoral]. Universitat Politècnica de València. doi:10.4995/Thesis/10251/90583 